\title{
Feasibility of Rotary Cup Atomizer for Slag Granulation
}

\author{
Toshio MIZUOCHI, Tomohiro AKIYAMA, Taihei SHIMADA, ${ }^{1)}$ Eiki KASAI ${ }^{1)}$ and Jun-ichiro YAGI ${ }^{1)}$ \\ Department of Chemical Engineering, Graduate School of Engineering, Osaka Prefecture University, Gakuen-cho, Sakai 599- \\ 8531 Japan. 1) Institute of Multidisciplinary Research for Advanced Materials (IMRAM), Tohoku University, Katahira, \\ Aoba-ku, Sendai, 980-8577 Japan.
}

(Received on June 4, 2001; accepted in final form on August 1, 2001)

\begin{abstract}
At the present molten slag from a blast furnace (B.F.) is granulated by impinging much water without any recovery of its much sensible heat $(1823 \mathrm{~K})$, polluting water and atmosphere. To solve these problems, we studied the dry granulation of molten slag by Rotary Cup Atomizer (RCA), in which the influence of the rotating speed of the RCA on slag drop size was mainly examined. In the experiment, the molten B.F. slag was supplied to the center of RCA with air blast. Slag drops flown from the cup lip due to centrifugal force were collected and examined from viewpoints of shape, dimension and the flown distance of the drop.

Most significantly, molten slag was successfully granulated under the dry conditions without water impingement. The rotating speed of the RCA influenced the diameter and shape of slag drop very strongly. The higher rotating speed made the slag drops smaller, more spherical and more uniform. Drops with 5 to $6 \mathrm{~mm}$ of average dimension were obtained at the rotating speed of $15 \mathrm{rps}(900 \mathrm{rpm})$, and drops with less than $1 \mathrm{~mm}$, at that of $50 \mathrm{rps}$ (3000 rpm). In the former case, the shape of drop obtained was distributed, changing from sphere to stick at the further place from the center of RCA. The results revealed a possibility of alternative, new slag granulation process with many benefits.
\end{abstract}

KEY WORDS: Ironmaking; molten slag; atomizer; cup form; rotating speed; slag composition; particle form.

\section{Introduction}

The steelmaking has by-produced a lot of molten slag of high temperature; about $300 \mathrm{~kg}$ per ton of pig iron. Conventionally, the Blast Furnace (B.F.) slag was treated by impinging much water for granulation and glassification. This treatment is mainly used for producing a raw material of the B.F. cement, aggregate and the roadbed.

However, this method has some serious problems to be overcome, as follows;

1) Too much water is necessary to granulate molten slag of high temperature.

2) An alkaline element in slag is polluting the water.

3) Sulfide is emitted from slag into the air by the water quenching.

4) A post process for drying slag is a must after the water quenching.

5) The thermal energy of high temperature slag is wasted without recovery. ${ }^{1-3)}$

Unfortunately, we did not construct the alternative effective method for solving these problems yet. In using slag as a raw material of cement, it must be quenched because glass structure is required. The granulation of slag is needed to make uniform glassification due to its low thermal conductivity. The point is that the dry slag granulation with quenching is necessary to solve the problems above mentioned because it keeps slag property as a raw material of cement. Furthermore, it is expected that slag particle diameter can be controlled, corresponding to the requirement of practical use.
For this purpose, the various atomizers were invented in the past ${ }^{4,5)}$; mainly, pressure atomizers, rotary atomizers, twin-fluid atomizers, etc., were re-examined. Rotary Cup Atomizer (RCA) was selected as the most suitable atomizer for granulating high temperature molten slag without water from the following merits:

1) The dry granulation of the high viscosity fluid such as oil is possible. ${ }^{4}$

2) The particle diameter is easily controllable.

3) The productivity of one unit equipment is largest.

4) The sensible heat of slag can be efficiently recovered by impinging reactive gas such as mixture of methane and steam. ${ }^{1-3)}$

The purpose of this paper, therefore, was to investigate a possibility of granulating B.F. slag by the RCA, in which influence of cup shape, cup speed, slag viscosity and gas flow rate on the granulation was mainly examined. The results would give hints for solving the problems of the conventional process and a possibility of the new slag treatment for environment preservation and energy saving.

\section{Experimental}

\subsection{Sample}

The sample prepared was B.F. slag; 33.8 mass $\% \mathrm{SiO}_{2}$, 15.2 mass $\% \mathrm{Al}_{2} \mathrm{O}_{3}, 42.9$ mass $\% \mathrm{CaO}, 6.8$ mass $\% \mathrm{MgO}$. The B.F. slag has $59.7(\mathrm{~J} / \mathrm{K} \cdot \mathrm{mol})$ in average specific heat, 0.035 to $0.105(\mathrm{~W} / \mathrm{m} \cdot \mathrm{K})$ in thermal conductivity and $0.44(\mathrm{~N} / \mathrm{s})$ in surface tension. ${ }^{6}$ Slag viscosity depends on chemical composition and temperature. It was evaluated by Iida's Eq. 
$(1)^{7)}$ :

$$
\begin{aligned}
& \mu=A \mu_{0} \exp \left(\frac{E}{B_{i}^{*}}\right) \\
& A=1.745-1.962 \times 10^{-3} T+7.000 \times 10^{-7} T^{2} \\
& E=11.11-3.65 \times 10^{-3} \mathrm{~T}
\end{aligned}
$$

Here, evaluation of $\mu_{0}$ and $B_{i}^{*}$ is calculated from relativelycomplicated equations. ${ }^{7)}$

The viscosity of slag calculated for $1773 \mathrm{~K}$ was 0.2 $(\mathrm{Pa} \cdot \mathrm{s})$.

\subsection{Method}

Figure 1 shows an experimental apparatus of the RCA. It consists of two parts; the RCA with a slag receiver and the slag supplier. In the RCA system, the slag supplier was placed at $2.16 \mathrm{~m}$ just above the RCA. The RCA has $50 \mathrm{rps}$ (3 $000 \mathrm{rpm}$ ) in maximum rotating speed, and $100 \mathrm{~mm}$ in cup diameter. Compressed air is sprayed into the molten slag through some nozzles for promoting granulation; it was placed concentrically $10 \mathrm{~mm}$ outside from the cup lip. The slag receiver with concentric partitions of $0.3,0.4,0.5$ and $0.6 \mathrm{~m}$ from the center of the cup was set around the cup to

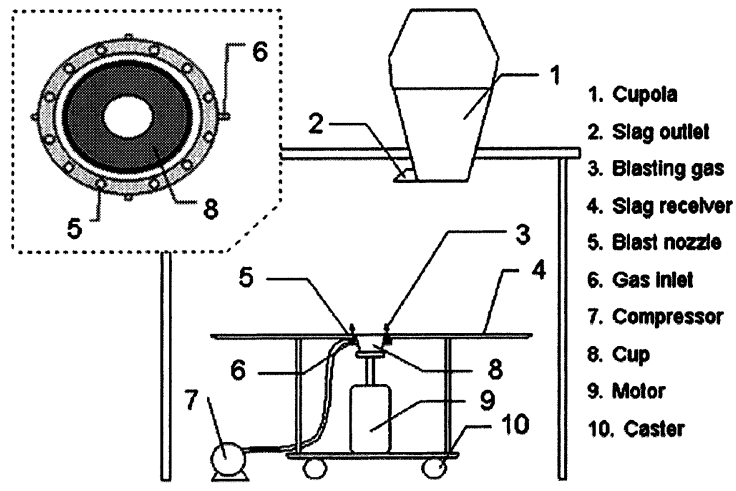

Fig. 1. Experimental apparatus of the RCA.

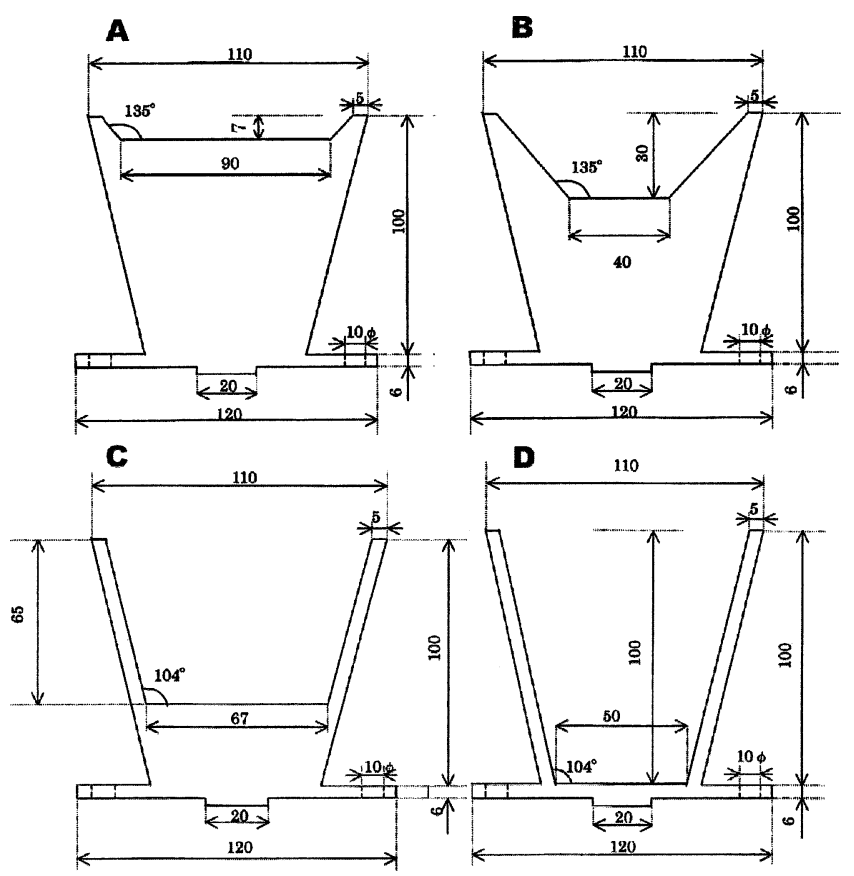

Fig. 2. Cups used shape of RCA. study a relationship between a position of the particle flown and the particle shape.

Figure 2 shows the four cups with different forms used as the RCA. The cups of A type and B type had a small inclination on the side and a shallow depth. In contrast, the cups of C type and D type had a large inclination of the side and a deep depth. The surface of an aluminum cup was coated by fireproof cement as thermal insulation.

During the experiments, the molten slag was poured into the center of the cup from a cupola with normal capacity of $1 \mathrm{t} / \mathrm{d}$ after the cup rotating speed reached constant; $15 \mathrm{rps}$ $(900 \mathrm{rpm})$ and $50 \mathrm{rps}$. The basic experiment conditions were 1673 to $1823 \mathrm{~K}$ in a slag temperature, $10 \mathrm{~g} / \mathrm{s}$ in a slag charging rate and $0.018 \mathrm{~kg} / \mathrm{s}$ in an air mass flowrate. After slag was granulated for a couple of minutes, the distribution of slag size in each zone of the receiver; 0 to $0.3,0.3$ to 0.4 , 0.4 to 0.5 , and 0.5 to $0.6 \mathrm{~m}$ in a distance from the center of the cup, was collected. The fifty drops of slag in the each zone were arbitrarily selected, and long and short diameters of the drop were measured one by one.

\section{Results and Discussion}

\subsection{Slag Form and Weight Distribution}

Figure 3 shows the photograph of slag discharged by centrifugal force at $15 \mathrm{rps}(900 \mathrm{rpm})$ of rotating speed. Strictly speaking, slag discharging from the cup was not steady state, because the molten slag was intermittently supplied to the cup. It was found that slag particles were distributed uniformly in the circumferential direction. They all were recovered for the following evaluation.

Table 1 gives the radial distribution of slag drop collected, which is based on mass per unit zone. This showed that

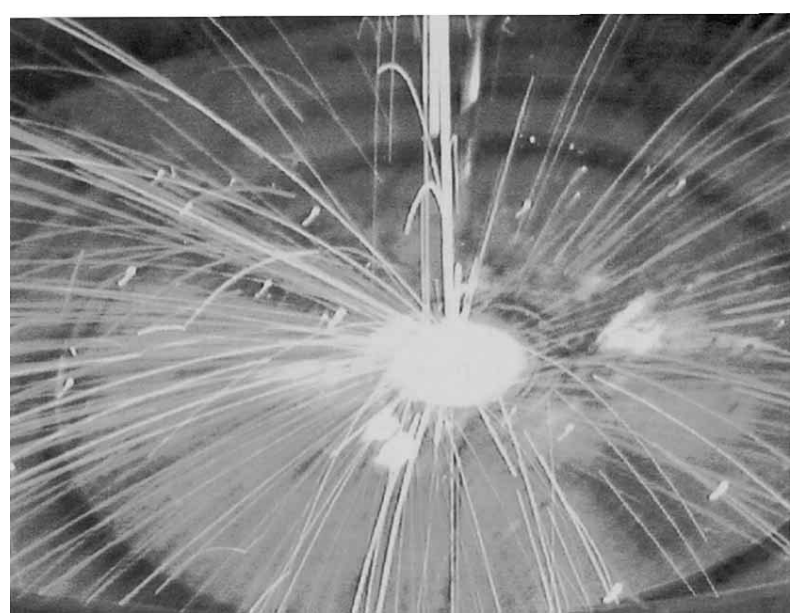

Fig. 3. Granulation of molten slag by using the RCA with $0.1 \mathrm{~m}$ diameter.

Table 1. Mass of BF slag obtained in a receiver under the condition of $15 \mathrm{rps}$ as rotating speed, in which the cup of B type was used.

\begin{tabular}{|c|c|c|c|c|}
\hline No. & Distance $(\mathrm{m})$ & Area $\left(\mathrm{m}^{2}\right)$ & Mass $(\mathrm{g})$ & Density $\left(\mathrm{g} / \mathrm{m}^{2}\right)$ \\
\hline 1 & $0-0.3$ & 0.283 & 160 & 565 \\
\hline 2 & $0.3-0.4$ & 0.22 & 120 & 545 \\
\hline 3 & $0.4-0.5$ & 0.283 & 130 & 459 \\
\hline 4 & $0.5-0.6$ & 0.346 & 190 & 549 \\
\hline
\end{tabular}



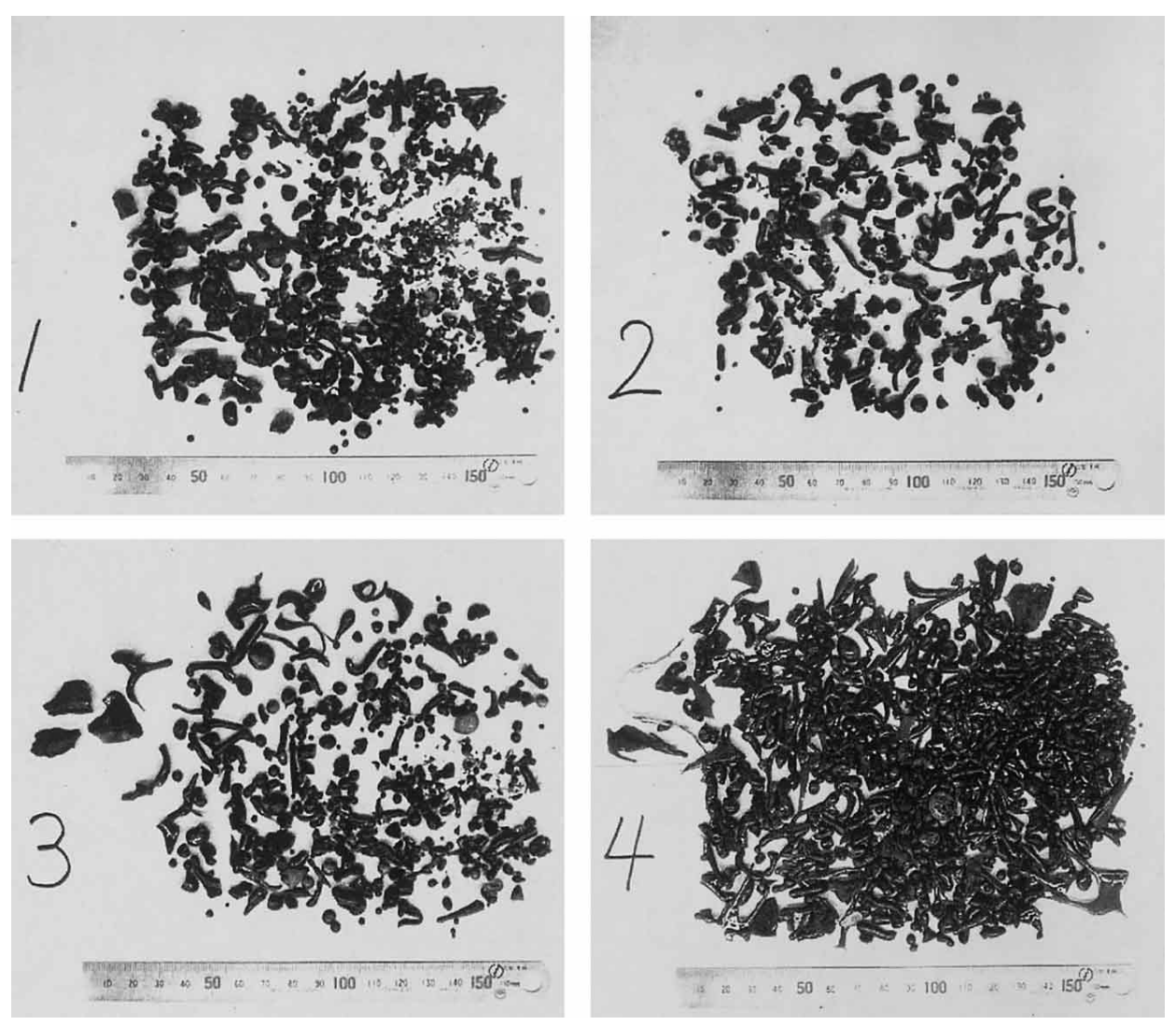

Fig. 4. Appearance of slag granulation by RCA under the rotating speed $15 \mathrm{rps}(900 \mathrm{rpm})$.

the largest density was zone No. 1, and the second one, No. 4. The reason why the zone No. 1 had the largest value was most likely due to unstable supply of the molten slag in the initial and final stages of the experiments.

Figure 4 is the collected particles, made at 15 rps of rotating speed by using the B type cup. Figure $\mathbf{5}$ is also the relationship between measured long diameter $\left(d_{1}\right)$ and short diameter $\left(d_{\mathrm{s}}\right)$ of the particles. In Figs. 4 and 5, figures of No. 1 to 4 correspond to each zone in Table 1; for example, No. 1 is the nearest zone from the cup center. The black slag in the photograph is probably caused by partial melting of the steel pipe of the slag supplier.

Obviously, the average long diameter of particles increased with increasing distance from the cup. In contrast, the average short diameter of particles was almost constant as $4.2 \pm 0.3 \mathrm{~mm}$. The average diameter of particles became bigger with flown distance of slag. Interestingly, the results of aspect ratio means that drop shape changed from spherical to ligamental.

According to the theory of RCA, the short diameter of particles was controllable by the liquid thickness of slag at the cup lip, and the long diameter of particles was length of liquid determined by the impinging air and/or the surface tension. Figure 5 shows clearly that a particle form was more spherical, when a particle diameter was less than 6 $\mathrm{mm}$ in the all of zone.

Figure 6 is a photograph of particles pulverized at $50 \mathrm{rps}$ (3000 rpm) of rotating speed by using the A type cup. The obtained particles were more uniform and smaller in comparison to that obtained at $15 \mathrm{rps}$, as shown in Fig. 7. An average diameter of particles decreased to $0.6 \mathrm{~mm}$ from 1.3 $\mathrm{mm}$ with increasing distance from the cup lip. The shape of

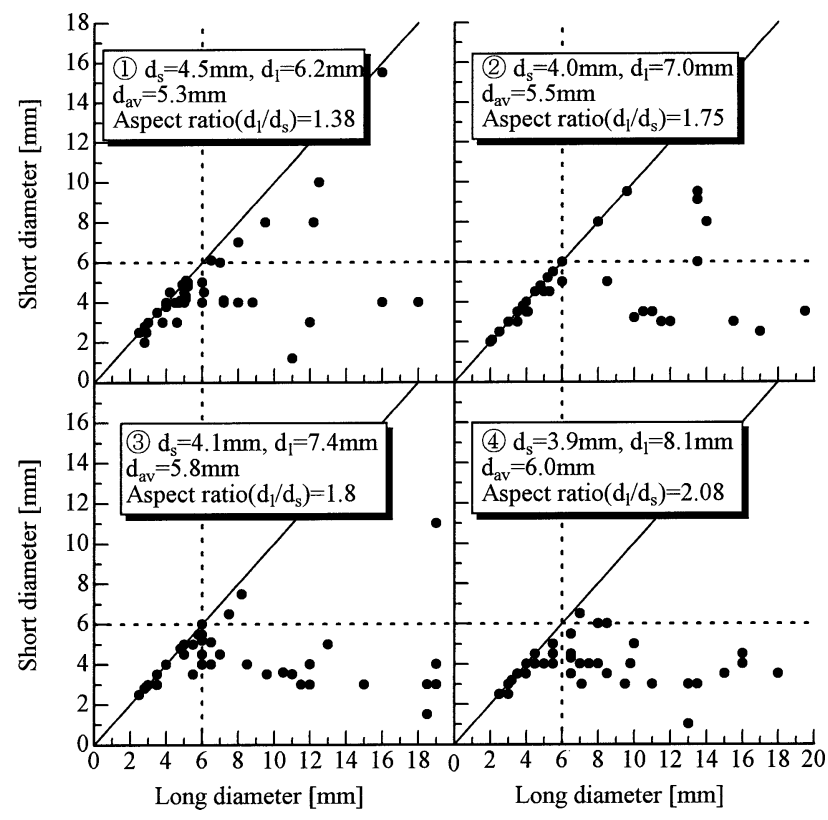

Fig. 5. Relationship between particle long diameter and short one under the rotating speed of $15 \mathrm{rps}(900 \mathrm{rpm})$.

the smaller particle became more spherical. This comparative analysis was done by using the two cups with different depth; $7 \mathrm{~mm}$ and $30 \mathrm{~mm}$, the same diameter of $110 \mathrm{~mm}$ and the same slope; $135^{\circ}$, of inner wall. Thus, strictly speaking, the results might include such influence slightly. The slag drops obtained under the conditions of this study was not glass structure, from its XRD patterns.

In particular, this slag granulation treatment with $50 \mathrm{rps}$ of rotating speed made successfully spherical small parti- 


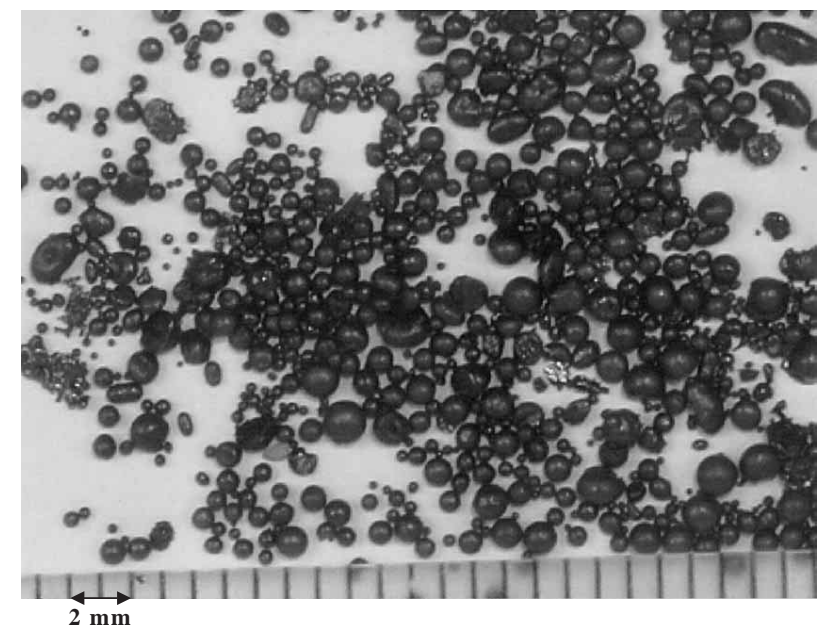

Fig. 6. Appearance of slag granulation by RCA under the rotating speed $50 \mathrm{rps}(3000 \mathrm{rpm})$.

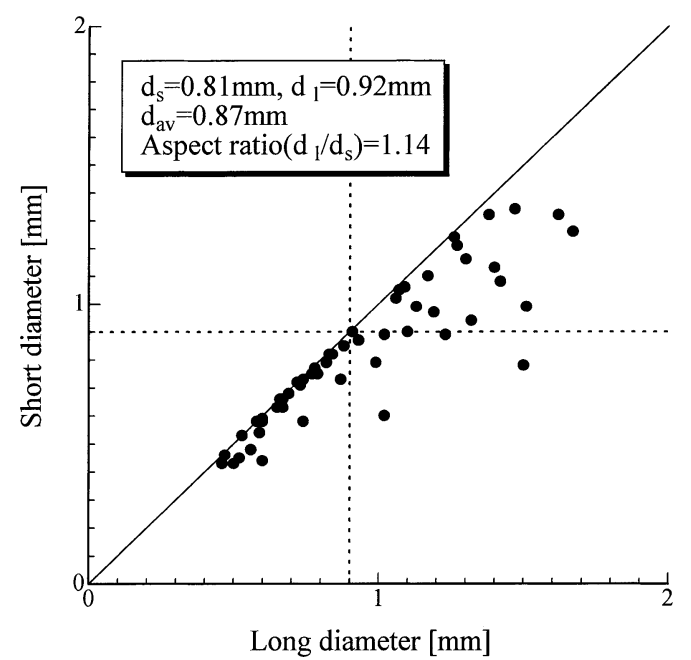

Fig. 7. Relationship between long particle diameter and short one under the rotating speed of $50 \mathrm{rps}(3,000 \mathrm{rpm})$.

Table 2. Mass of BF slag obtained in a receiver under the condition of $50 \mathrm{rps}$ as rotating speed, in which the cup of A type was used.

\begin{tabular}{|c|c|c|c|c|}
\hline No. & Distance $(\mathrm{m})$ & Area $\left(\mathrm{m}^{2}\right)$ & Mass $(\mathrm{g})$ & Density $\left(\mathrm{g} / \mathrm{m}^{2}\right)$ \\
\hline 1 & $0-0.3$ & 0.283 & 33.2 & 117 \\
\hline 2 & $0.3-0.4$ & 0.22 & 9.6 & 43.7 \\
\hline 3 & $0.4-0.5$ & 0.283 & 18.6 & 65.8 \\
\hline 4 & $0.5-0.6$ & 0.346 & 31.7 & 91.7 \\
\hline
\end{tabular}

cles with less $0.9 \mathrm{~mm}$ in dimension. It is concluded that size distribution of particles decreased with increasing the rotating speed.

Table 2 indicates mass of slag collected in each zone at $50 \mathrm{rps}$ of rotating speed. Here, difference of total amount of the slag recovered, given in Table 1 and Table 2, was caused by difference of the collecting time. In comparison to Table 1 , there is appreciable difference among the four zone. The slag mass density in zone of No. 1 was biggest among four zones and that in zone of No. 2 to 4 increased with flown distance of slag by increasing from $15 \mathrm{rps}$ to $50 \mathrm{rps}$ in rotating speed.
Table 3. Properties of slag employed for calculation.

\begin{tabular}{|c|c|c|c|c|c|}
\hline Symbol & Value & Unit & Symbol & Value & Unit \\
\hline$\gamma$ & $0.44(440)$ & $\mathrm{kg} / \mathrm{s}^{2}$ & $m_{l}$ & $0.02(20)$ & $\mathrm{kg} / \mathrm{s}$ \\
\hline$v_{\perp}$ & $0.75 \cdot 10^{-4}(0.75)$ & $\mathrm{m}^{2} / \mathrm{s}$ & $\mathrm{m}_{\mathrm{g}}$ & $0.018(18)$ & $\mathrm{kg} / \mathrm{s}$ \\
\hline$v_{\text {water }}$ & $1.79 \cdot 10^{-6}\left(1.79 \cdot 10^{-2}\right)$ & $\mathrm{m}^{2} / \mathrm{s}$ & Q & $2.86 \cdot 10^{-7}(28.6)$ & $\mathrm{m}^{3} / \mathrm{s}$ \\
\hline$\rho_{8}$ & $1.29\left(1.29 \cdot 10^{-3}\right)$ & $\mathrm{kg} / \mathrm{m}^{3}$ & $\mathrm{Vg}$ & $1(100)$ & $\mathrm{m} / \mathrm{s}$ \\
\hline $\mathrm{a}$ & $0.01(1)$ & $\mathrm{m}$ & $\rho_{L}$ & $2800(2.8)$ & $\mathrm{kg} / \mathrm{m}^{3}$ \\
\hline $\mathrm{d}_{\mathrm{L}}$ & $0.1(10)$ & $\mathrm{m}$ & $\mathrm{N}$ & 8 to 54 & rps \\
\hline $\mathrm{T}$ & 1723 & $\mathrm{~K}$ & & & \\
\hline
\end{tabular}

( ) is the value of c. g. s. unit.

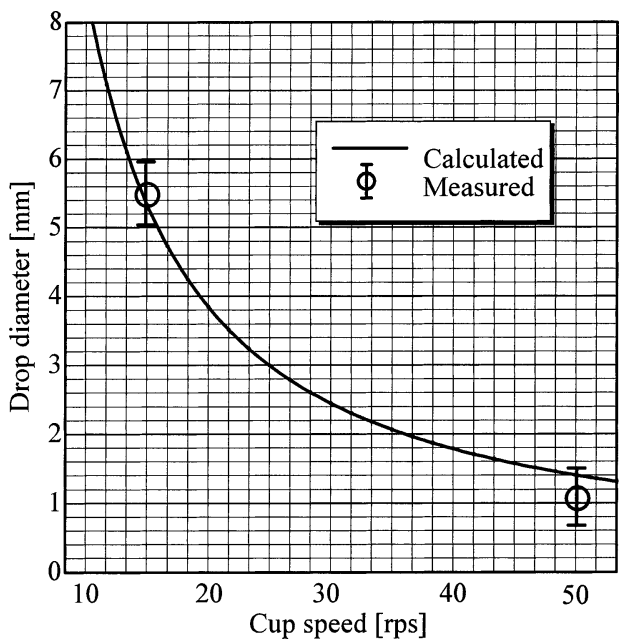

Fig. 8. Comparison of measured drop diameter with calculated one by an empirical equation.

\subsection{Empirical Equation for the Particle Diameter Evaluation}

Frazer $^{8-11)}$ researched the RCA for the granulation of high viscosity oil; the kinetic viscosity was 6 to $165 \times 10^{-6}$ $\left(\mathrm{m}^{2} / \mathrm{s}\right)$. In his paper, the liquid granulation by blasting air to a liquid sheet from the lip of cup was discussed and the Eq. (2) for evaluating diameter finally was derived, in which coefficients were determined from many experiments, and semi-empirical equations were also derived (see appendix).

$$
\begin{aligned}
d_{\text {sauter }}= & 6 \times 10^{-4}+\frac{0.59 \gamma^{0.5} v_{\mathrm{r}}^{0.21}}{\rho_{\mathrm{g}}^{0.5}\left(a d_{\mathrm{L}}+a^{2}\right)^{0.25}}\left[1+\frac{0.065}{M_{\mathrm{R}}^{1.5}}\right] \\
& \times\left[\frac{Q}{V_{\mathrm{T}}^{3}\left(0.5 V_{\mathrm{R}}^{2}-V_{\mathrm{R}}+1\right)}\right]^{1 / 2} \quad(\mathrm{~cm}) \ldots \ldots \ldots \ldots \ldots . .
\end{aligned}
$$

Here, the parameters are expressed by the c.g.s. unit system.

The particle diameter of these equations is given by Sauter average diameter, $d_{\mathrm{s}}$. The $d_{\mathrm{s}}$, defined as the volumeto-surface-area average diameter, is determined by dividing the volume by the surface area. The results calculated by this empirical Eq. (2) were compared with measured ones, under the conditions given in Table 3. Note that kinetic viscosity of molten slag is within the experimental conditions of Frazer's work.

Figure 8 shows the measured slag diameter and the calculated one by the Eq. (2). As expected, the predicted curve agreed with the measured data. Reliable data is, unfortunately, not enough for deriving new equation. Thus, assuming that the Frazer's equation is application to slag granulation, the particle diameter is controllable by cup speed, 


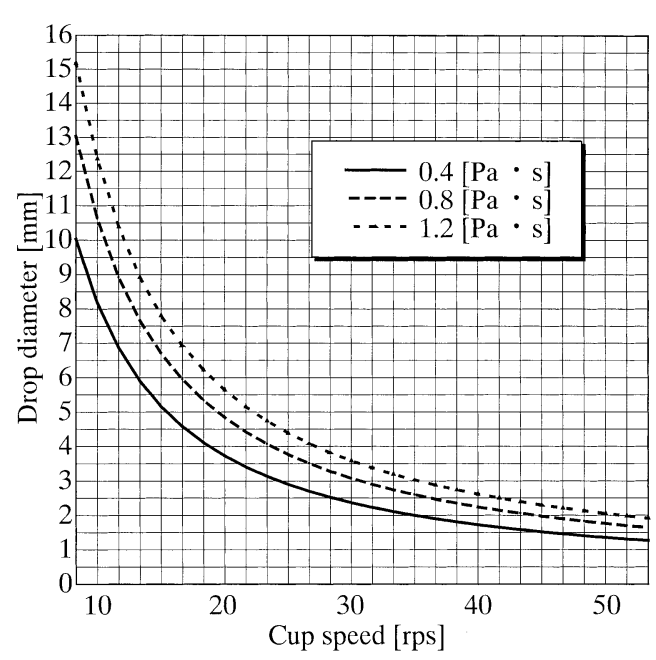

Fig. 9. Effect of slag viscosity on drop diameter.

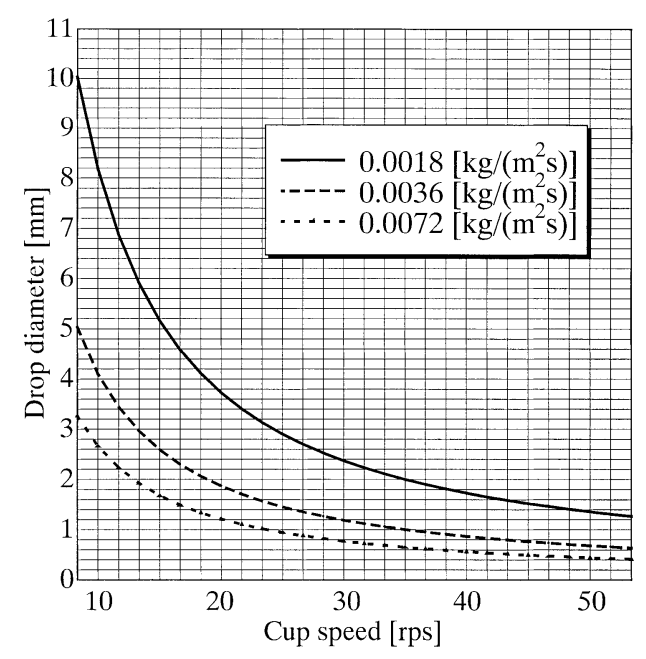

Fig. 10. Effect of gas mass flowrate on drop diameter.

strongly for less $25 \mathrm{rps}$ (1500 rpm) and gradually for over $25 \mathrm{rps}$. The results showed clearly that the rotating speed of the cup is an important operating parameter to control the particle size.

The cups of C type and D type shown in Fig. 2 could not granulate slag successfully because of failure in slag discharging even at large rotating speed. This was mainly caused by a fact that influence of gravity force on slag was relatively larger than centrifugal one, when the depth of the cup was too deep with steep inner wall. We, thus, concluded that the slag granulation is promoted by using the shallower cup with gentler inner wall.

\subsection{Influence of Viscosity and Gas Mass Flowrate of Molten Slag on Slag Drop Diameter}

Temperature and chemical composition of slag influence greatly on the slag viscosity. In addition, the influence of slag viscosity on granulation is crucial. Figure 9 is drop diameter calculated by the Eq. (2) under the different conditions of slag viscosity. The drop diameter increased with increasing the viscosity. Especially when the rotating speed was low, the influence on the drop diameter was sensitive. It was found that the influence of viscosity on the drop diameter is one of the most sensitive operating parameters. Thus, for obtaining the desired drop diameter, it is crucial to con- trol temperature and chemical composition of slag; main parameters for viscosity.

Figure 10 shows an effect of gas mass flowrate on drop diameter. Gas mass flowrate had also influence on the drop diameter. The diameter became smaller with increasing gas mass flowrate. The result showed that gas mass flow rate had more influence on granulation, in comparison to slag viscosity. We concluded that drop form was controllable by three parameters; the slag property, rotating speed and gas mass flowrate.

Regarding to the RCA for slag granulation, two papers $^{12,13)}$ and one patent ${ }^{14)}$ were published by British in 1985. The main objective of them was to exchange heat of slag by blasting air and not granulate slag finely. They were greatly contributed to application of the RCA to very viscous fluid like slag for the first time. However, influence of operating conditions on the slag drops has never explained well. At the present, the dry slag granulation process is not continuously operated, although some equipment has been constructed.

To industrialize this one, we should pay much more attention to high productivity per unit area, and high recovery ratio of thermal energy by using chemical reaction, not by stream generation. According to one report, ${ }^{15}$ ) financial evaluation of the dry slag granulation is on lower side (\$2.64/t-slag), in comparison to the wet one (\$6.51/t-slag).

\section{Conclusions}

The possibility of granulation of B.F. molten slag by RCA was experimentally validated;

1) The RCA made slag granulated successfully without water impingement.

2) In using the shallow cup, the smaller slag drop than 1 $\mathrm{mm}$ was obtained by increasing cup speed, increasing gas flowrate and lowering slag viscosity.

3) The size of slag drop obtained was almost explained by Frazer's empirical equation.

\section{Nomenclature}

$a$ : Radial distance of air blast from cup lip (m)

$A$ : $\quad$ Parameter determined experimental date $(\mathrm{K})$

$B_{i}^{*}:$ Modified basicity index (-)

$d_{1}$ : Long diameter of drop (mm)

$d_{\mathrm{L}}:$ Diameter of cup lip (m)

$d_{\mathrm{s}}$ : Short diameter of drop $(\mathrm{mm})$

$d_{\text {sauter }}$ : Sauter mean diameter $(\mathrm{mm})$

$E$ : $\quad$ Parameter determined experimental date $(\mathrm{K})$

$m_{\mathrm{g}}$ : Gas mass flowrate $(\mathrm{kg} / \mathrm{s})$

$m_{\mathrm{L}}: \quad$ Liquid mass flowrate $(\mathrm{kg} / \mathrm{s})$

$M_{\mathrm{R}}$ : Mass flow ratio $\left(m_{\mathrm{L}} / m_{\mathrm{g}}\right)(-)$

$N$ : Cup speed (rps)

$Q:$ Liquid volumetric flow rate $\left(\mathrm{m}^{3} / \mathrm{s}\right)$

$S$ : Sheet thickness (m)

$T: \quad$ Temperature $(\mathrm{K})$

$u_{\mathrm{m}}$ : Mean radial velocity of liquid along wall of cup $(\mathrm{m} / \mathrm{s})$

$V_{\mathrm{g}}:$ Velocity of gas $(\mathrm{m} / \mathrm{s})$

$V_{\mathrm{R}}$ : Velocity ratio $\left(V_{\mathrm{g}} / V_{\mathrm{T}}\right)(-)$

$V_{\mathrm{T}}$ : Velocity of liquid film leaving cup lip (m/s) 


\section{Greek symbol}

$\gamma:$ Liquid surface tension $\left(\mathrm{kg} / \mathrm{s}^{2}\right)$

$\varepsilon$ : Angle between the radical velocity component and the resultant liquid velocity of the sheet at the cup $\operatorname{lip}\left({ }^{\circ}\right)$

$\theta: \quad$ Half angle of divergence of cup $\left(^{\circ}\right)$

$\lambda$ : Wave-length $(\mathrm{m})$

$\mu$ : Prediction viscosity of slag $\left(\mathrm{kg} / \mathrm{m}^{2}\right)$

$\mu_{0}$ : Viscosity of non-network forming hypothetical melt $\left(\mathrm{kg} / \mathrm{m}^{2}\right)$

$v_{\mathrm{L}}:$ Kinematic liquid viscosity $\left(\mathrm{m}^{2} / \mathrm{s}\right)$

$v_{\text {water }}$ : Kinematic viscosity of water $\left(\mathrm{m}^{2} / \mathrm{s}\right)$

$v_{\mathrm{r}}$ : Kinematic viscosity ratio $\left.v_{\mathrm{L}} / v_{\text {water }}\right)(-)$

$\rho_{\gamma}:$ Gas density $\left(\mathrm{kg} / \mathrm{m}^{3}\right)$

\section{Acknowledgements}

This research was supported by the Ministry of Education, Science and Culture, Japan (Grant-in-aid for Scientific Research on Priority Areas, A 12015247 and Basic Research, B 11555196), and ISIJ (11th Research Promotion Grant).

\section{REFERENCES}

1) E. Kasai, T. Kitajima, T. Akiyama, J. Yagi and F. Saito: ISIJ Int., 37 (1997), 1031

2) T. Shimada, V. Kochura, T. Akiyama, E. Kasai and J. Yagi: ISIJ Int., 41 (2001), 111

3) T. Akiyama and T. Mizuochi: Kankyoukagakukai, special Number. 14 (2001), No. 2, 143.

4) H. Lefebve: Atomization and Sprays, Hemisphere Publishing Corporation, New York, (1989) 2.

5) Robert H. Perry and Don Green: Perry's Chemical Engineers' Handbook Vol. 6, McGraw-Hill Publishing Company, New York, (1984), 18

6) Tekko-Binran: Ironmaking Steelmaking; Vol. 3, ed. by ISIJ, Maruzen, Tokyo, (1979), 319.

7) T. Iida, H. Sakai, Y. Kita, and K. Sugino: ISIJ Int., 40 (2000) Supplements, S110.

8) R. P. Frazer, N. Dombrowski and J. H. Routley: J. Inst. fuel, (1963), 316.

9) R. P. Frazer, N. Dombrowski and J. H. Routley: Chem. Eng. Sci., 18 (1963), 315.

10) R. P. Frazer, N. Dombrowski and J. H. Routley: Chem. Eng. Sci., 18 (1963) 323.

11) R. P. Frazer, N. Dombrowski and J. H. Routley: Chem. Eng. Sci., 18 (1963) 339.

12) N. Hay, S. J. Pickering and G. H. Yhomas: ImechE, C133185,
(1985), 107.

13) S. J. Pickering, N. Hay, T. F. Roylance and G. H. Thomas: Ironmaking Steelmaking, 12 (1985), 14.

14) UK Patent Application; GB21048330A, (1985).

15) The Japan Iron and Steel Federation: Private communication, (1999).

\section{Appendix}

The wavelength $\lambda$ of liquid discharged from the cup may be written as

$$
\lambda=\frac{2 \pi \gamma}{\rho_{\mathrm{g}}\left(V_{\mathrm{T}}^{2}-V_{\mathrm{g}} V_{\mathrm{T}}+\frac{V_{\mathrm{g}}^{2}}{2}\right)}
$$

from which the particle diameter, $d$, was given by,

$$
\begin{aligned}
d_{\text {sauter }}= & \text { const } \cdot\left[\frac{\gamma S}{\rho_{\mathrm{g}}\left(V_{\mathrm{T}}^{3}-V_{\mathrm{g}} V_{\mathrm{T}}+\frac{V_{\mathrm{g}}^{2}}{2}\right)}\right]^{1 / 2} \\
d_{\text {sauter }}= & 6 \times 10^{-4}+\frac{1.4 \gamma^{0.5} v_{\mathrm{r}}^{0.21}}{\rho_{\mathrm{g}}^{0.5}}\left[1+\frac{0.065}{M_{\mathrm{R}}^{1.5}}\right] \\
& \times\left[\frac{S}{V_{\mathrm{T}}^{3}\left(0.5 V_{\mathrm{R}}^{2}-V_{\mathrm{R}}+1\right)}\right]^{1 / 2} \ldots \ldots \ldots \ldots \ldots \ldots \ldots \ldots \ldots
\end{aligned}
$$

The liquid thinness $S$ at the point of the air blast was given by

$$
\begin{aligned}
& S=\frac{Q}{2 \pi V_{\mathrm{T}}}\left[\frac{d_{\mathrm{L}}^{2} u_{\mathrm{m}}^{2}}{4 V_{\mathrm{T}}^{2}}+a d_{\mathrm{L}}+a^{2}\right]^{1 / 2} \\
& u_{\mathrm{m}}=\left[\frac{2 Q^{2} N^{2} \sin \theta}{3 d_{\mathrm{L}} v_{\mathrm{r}}}\right]^{1 / 3} \\
& \sin \varepsilon=\frac{u_{\mathrm{m}}}{V_{\mathrm{T}}}
\end{aligned}
$$

The definition was that $u_{\mathrm{m}}=V_{\mathrm{T}}$ at the time of $\varepsilon=90^{\circ}$. 